\title{
Discovery of Mandelalide E and Determinants of Potent Cytotoxicity for the Mandelalide Series.
}

\author{
Mohamad Nazari, ${ }^{a}$ Jeffrey D. Serrill, ${ }^{a}$ Justyna Sikorska, ${ }^{a}$ Tao Ye, ${ }^{b}$ Jane E. Ishmael, ${ }^{*, a}$ \\ and Kerry L. McPhail., ${ }^{*}$ \\ ${ }^{a}$ Department of Pharmaceutical Sciences, Oregon State University, 203 Pharmacy Building, Corvallis, \\ OR. 97331-4003, United States, 'baboratory of Chemical Genomics, School of Chemical Biology and \\ Biotechnology, Peking University Shenzhen Graduate School Xili, Nanshan District, Shenzhen, 518055, \\ China
}

\section{SUPPORTING INFORMATION}




\section{Table of Contents}

Isolation and Structure Elucidation Materials and Methods ….........................................................

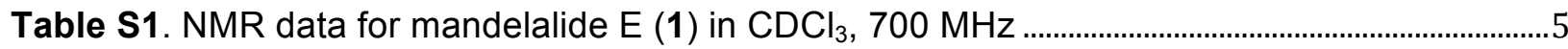

Figure S1. ${ }^{1} \mathrm{H}$ NMR spectrum for mandelalide $\mathrm{E}\left(1,700 \mathrm{MHz}, \mathrm{CDCl}_{3}\right)$................................................

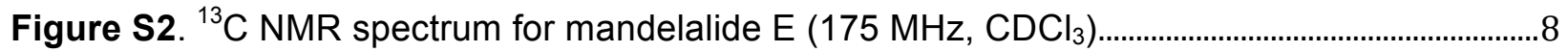

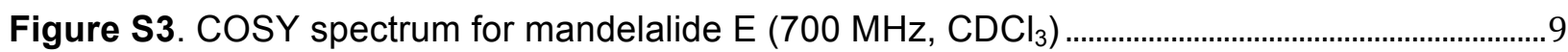

Figure S4. HSQC spectrum for mandelalide $\mathrm{E}\left(700 \mathrm{MHz}, \mathrm{CDCl}_{3}\right)$....................................................10

Figure S5. Phase-cycled HMBC spectrum for mandelalide $\mathrm{E}\left(700 \mathrm{MHz}, \mathrm{CDCl}_{3} ;{ }^{2,3} \mathrm{~J}_{\mathrm{CH}}=8 \mathrm{~Hz}\right) .11$

Figure S6. TOCSY spectrum for mandelalide $\mathrm{E}$, mixing time $=80 \mathrm{~ms}\left(500 \mathrm{MHz}, \mathrm{CDCl}_{3}\right) \ldots \ldots \ldots . . .12$

Figure S7. NOESY spectrum for mandelalide $\mathrm{E}\left(500 \mathrm{MHz}, \mathrm{CDCl}_{3}\right.$, mixing time $\left.=800 \mathrm{~ms}\right) \ldots \ldots . . .13$

Figure S8. Key NOESY correlations for the mandelalide E glycoside. Dashed lines indicate weak NOESY correlations versus solid lines for prominent correlations

Biological Evaluation Materials and Methods

Figure S9. HPLC profile for A) synthetic mandelalide A provided by Professor Tao $\mathrm{Ye},{ }^{2}$ and $\mathrm{B}$ ) co-injection of synthetic Ye product and natural mandelalide $A^{1}$.

Figure S10. CD spectra in $\mathrm{MeOH}$ for: A) synthetic mandelalide $A(4 \mathrm{mg} / \mathrm{mL}),{ }^{2}$ and $\left.B\right)$ natural mandelalide $\mathrm{A}(0.5 \mathrm{mg} / \mathrm{mL}){ }^{1}$

Concentration-Response Curves for Natural Mandelalides 16

Figure S12. Relationship of cell density to mandelalide A-induced cytotoxicity.

Concentration-response relationships for natural mandelalide $A^{1}$ (dashed line, not re-purified) and a synthetic mandelalide $A^{2}$ (purified) 


\section{Isolation and Structure Elucidation Materials and Methods}

General Experimental. Optical rotations were measured on a Jasco P-1010 polarimeter. UV spectra were measured on a SpectraMax190 (Molecular Devices). Circular dichroism (CD) spectra were recorded on a Jasco J-815 instrument (scan rate $100 \mathrm{~nm} \mathrm{~min}^{-1}$ ) from $\mathrm{MeOH}$ solutions in a cell with $1 \mathrm{~mm}$ path length. NMR data were acquired in $\mathrm{CDCl}_{3}$ referenced to internal TMS signals (0.00 ppm) on a Bruker Avance III $700 \mathrm{MHz}$ spectrometer equipped with a $5 \mathrm{~mm}{ }^{13} \mathrm{C}$ cryogenic probe. High-resolution ESI mass spectrometry was performed in positive ion mode on a 6230 TOF mass spectrometer (Agilent Technologies, Santa Clara, CA). LC-ESIMS data were obtained on an ABSciex 3200 QTrap mass spectrometer. HPLC was performed using a Shimadzu dual LC-20AD solvent delivery system with a Shimadzu SPD-M20A UV/VIS photodiode array detector.

Extraction and Isolation. The ascidian, Lissoclinum sp. ${ }^{1}$ (Ascidiacea, Aplousobranchia, Didemnidae) was collected by hand using SCUBA at a depth of $18 \mathrm{~m}$ (July 7, 2013) from White Sands Reef in Algoa Bay, Eastern Cape Province, South Africa (33:59.916S, 25:42.573W). The type specimen for this ascidian species is housed at the South African Institute for Aquatic Biodiversity (SAIAB), Grahamstown, South Africa.

The freeze-dried organism $(74.4 \mathrm{~g})$ was extracted with $2: 1 \mathrm{CH}_{2} \mathrm{Cl}_{2}-\mathrm{MeOH}$ yielding $1.6 \mathrm{~g}$ of organic extract. This organic extract was fractionated on Sephadex $\mathrm{LH}-20\left(\mathrm{CH}_{2} \mathrm{Cl}_{2}-\mathrm{MeOH}, 1: 3\right)$ to give 50 fractions, of which combined fractions 17 and 18 were subjected to reversed phase $\mathrm{C}_{18}$ solid phase extraction ( $\mathrm{RP}_{18} \mathrm{SPE}$ ) using a stepped gradient of 55 and $100 \% \mathrm{MeCN}$ in $\mathrm{H}_{2} \mathrm{O}$. The $55 \% \mathrm{MeCN}_{-} \mathrm{H}_{2} \mathrm{O}$ and $100 \% \mathrm{MeCN}$ fractions were further separated by RP HPLC (Synergi Hydro-RP, Phenomenex, $250 \mathrm{~mm}$ x $10 \mathrm{~mm}, 7: 3 \mathrm{MeCN}$ in $\left.\mathrm{H}_{2} \mathrm{O}\right)$ to yield mandelalides $\mathrm{E}(1,0.8$ $\mathrm{mg}), \mathrm{B}(3,0.5 \mathrm{mg})$, and $\mathrm{C}(4,0.8 \mathrm{mg}) . \mathrm{RP}_{18} \mathrm{SPE}$ of the combined LH20 fractions 19-23 using $100 \% \mathrm{MeOH}$, followed by RP HPLC (Synergi Hydro-RP, Phenomenex, $250 \mathrm{~mm} \times 10 \mathrm{~mm}, 4: 6$ to 7:3 $\mathrm{MeCN}$ in $\left.\mathrm{H}_{2} \mathrm{O}\right)$, subsequently yielded mandelalides $\mathrm{A}(2,1.7 \mathrm{mg})$ and $\mathrm{B}(3,2.5 \mathrm{mg})$. 
Mandelalide A. Amorphous solid; $[\alpha]^{19}{ }_{D}-7 \quad(c=0.20 \text {, MeOH); LR-ESI-MS m/z [M+Na }]^{+} 647.4$; HR-ESI-MS m/z [M+Na] ${ }^{+}$647.3396, (calcd for $\mathrm{C}_{33} \mathrm{H}_{52} \mathrm{O}_{11} \mathrm{Na}, 647.3407$ ); ${ }^{1} \mathrm{H}$ and ${ }^{13} \mathrm{C}$ NMR were consistent with reported data. ${ }^{1}$

Mandelalide B. Amorphous solid; $[\alpha]^{23}-11(c=0.45, \mathrm{MeOH})$; LR-ESI-MS $\mathrm{m} / \mathrm{z}[\mathrm{M}+\mathrm{Na}]^{+}$733.4; HR-ESI-MS m/z [M+Na] ${ }^{+} 733.3748$, (calcd for $\mathrm{C}_{37} \mathrm{H}_{58} \mathrm{O}_{13} \mathrm{Na}, 733.3775$ ); ${ }^{1} \mathrm{H}$ and ${ }^{13} \mathrm{C}$ NMR were consistent with reported data. ${ }^{1}$

Mandelalide C. Amorphous solid; $[\alpha]^{21}{ }_{D}-9 \quad(c=0.30, \mathrm{MeOH})$; LR-ESI-MS m/z [M+Na] $]^{+}$589.3; HR-ESI-MS m/z [M+Na] ${ }^{+} 589.2979$, (calcd for $\mathrm{C}_{30} \mathrm{H}_{46} \mathrm{O}_{10} \mathrm{Na}, 589.2989$ ); ${ }^{1} \mathrm{H}$ and ${ }^{13} \mathrm{C}$ NMR were consistent with reported data. ${ }^{1}$

Mandelalide E. Amorphous solid; $[\alpha]^{23}{ }_{D}-2.1(c=0.40, \mathrm{MeOH}) ; \mathrm{UV}(\mathrm{MeOH}) \lambda_{\max }(\log \varepsilon) 280$ (2.7), 227 (3.9); LR-ESI-MS m/z [M+Na] 819.4; HR-ESI-MS m/z [M+Na] $]^{+}$819.3796, (calcd for $\mathrm{C}_{41} \mathrm{H} 64 \mathrm{O}{ }_{15} \mathrm{Na}, 819.4243$ ); ${ }^{1} \mathrm{H}$ and ${ }^{13} \mathrm{C}$ NMR, COSY, HMBC, TOCSY, ROESY (Table S1). 
Table S1. NMR data for mandelalide $\mathrm{E}(1)$ in $\mathrm{CDCl}_{3}, 700 \mathrm{MHz}$

\begin{tabular}{|c|c|c|c|c|c|c|}
\hline No. & $\delta_{C}($ mult $)$ & $\delta_{\mathrm{H}}(\mathrm{J}$ in $\mathrm{Hz})$ & cosy & $\mathrm{HMBC}^{\mathrm{a}}$ & NOESY & TOCSY \\
\hline 1 & $176.3(\mathrm{~s})$ & - & & & & \\
\hline 2 & $81.0(\mathrm{~s})$ & - & & & & \\
\hline 3 & $69.6(d)$ & $4.11(\mathrm{br} \mathrm{m})$ & $4 \mathrm{~b}$ & 4 & $4 a, 4 b, 5$ & $4 a, 4 b, 5,6 a x, 6 e q, 7,10 a$ \\
\hline $4 a$ & $38.2(\mathrm{t})$ & $1.99(o b)$ & $3,4 b, 5$ & & $4 b$ & 4b, 6ax, 6eq, 7, 8ax, 8eq, OH-2 \\
\hline $4 \mathrm{~b}$ & & $1.72(\mathrm{~m})$ & $3,4 a, 5$ & 3 & $4 a, 7$ & $4 a, 6 a x, 6 e q, 7,8 a x, 8 e q, O H-2$ \\
\hline 5 & $72.9(d)$ & $3.55\left(\mathrm{~m}^{\mathrm{b}}\right)$ & $4 a, 6 a x$ & 6 & $3,4 a, 4 b, 9,16 a, 23$ & 4a, 4b, 6ax, 6eq, 8ax, 9, OH-2 \\
\hline $6 a x$ & $37.4(\mathrm{t})$ & $1.17\left(\mathrm{~m}^{\mathrm{b}}\right)$ & 5,6 eq, 7 & 5,7 & $3,4 b, 6 e q, 7$ & $4 a, 4 b, 5,6 e q, 7,8$ eq, $8 a x, 9$ \\
\hline $6 e q$ & & $1.98(o b)$ & $5,6 a x, 7$ & & $6 a x, 1^{\prime}$ & $4 a, 4 b, 5,6 a x, 7,8 e q, 8 a x, 9$ \\
\hline 7 & $72.6(d)$ & $3.80(\mathrm{~m})$ & $6 a x, 6 e q, 8 a x, 8 e q$ & & $1^{\prime}, 5^{\prime}, 6$ eq, 8eq, 9 & $4 a, 4 b, 6 a x, 6 e q, 8 a x, 8 e q, 9,10 a, 10 b$ \\
\hline $8 a x$ & $38.9(\mathrm{t})$ & $1.26(\mathrm{ob})$ & 7,8 eq, 9 & 9 & $8 e q$ & $5,6 e q, 6 a x, 7,8 e q, 9,10 a, 10 b, 11,25$ \\
\hline $8 e q$ & & $1.90(\mathrm{~m})$ & $7,8 a x$ & & $8 a x, 7,1^{\prime}$ & $5,6 e q, 6 a x, 7,8 a x, 9,10 a, 10 b, 11,25$ \\
\hline 9 & $72.3(d)$ & $3.40(\mathrm{~m})$ & $8 a x, 10 a, 10 b$ & & $5,10 a, 10 b, 25$ & $6 a, 8 a x, 8 e q, 10 a, 10 b, 11,25,26$ \\
\hline $10 a$ & $43.0(t)$ & $1.57(\mathrm{ob})$ & $9,10 b 11$ & & $10 b$ & $\begin{array}{l}\text { 5, 6ax, } 7,8 a x, 8 e q, 10 b, 11,12,13,14,15,16 a, 16 b, 19 a \\
19 b, 22 a, 22 b, 25\end{array}$ \\
\hline $10 \mathrm{~b}$ & & $1.37(\mathrm{~m})$ & $9,10 a, 11$ & 25 & $9,10 a, 11,19 a, 21$ & $\begin{array}{l}\text { 5, 6ax, } 7,8 a x, 8 e q, 10 a, 11,12,13,14,15,16 a, 16 b, 19 a \\
19 b, 22 a, 22 b, 25\end{array}$ \\
\hline 11 & $32.8(d)$ & $2.42\left(m^{c}\right)$ & $10 a, 10 b, 12,25$ & 25 & $10 a, 12,13,23$ & $8 a x, 8 e q, 10 a, 10 b, 12,13,14,15,16 a, 18,22 a, 22 b$ \\
\hline 12 & $140.6(d)$ & $5.64(\mathrm{dd}, 15.0,8.7)$ & 11,13 & $11,14,25$ & $11,13,14,25$ & $9,10 a, 10 b, 11,13,14,15,16 a, 16 b, 17,22 a, 25,26$ \\
\hline 13 & $123.4(d)$ & $6.37(\mathrm{dd}, 15.0,11.2)$ & 12,14 & 11,14 & $11,12,14^{*}, 16 a, 21,25$ & $9,10 a, 10 b, 11,12,14,15,16 a, 16 b, 17,22 a, 25,26$ \\
\hline 14 & $130.6(d)$ & $6.13(\mathrm{dd}, 11.2,10.7)$ & $13,15,16 b$ & 12,16 & $12,13^{*}, 15$ & $9,10 a, 10 b, 11,12,13,15,16 a, 16 b, 17,22 a, 25,26$ \\
\hline 15 & $127.3(d)$ & $5.34(\mathrm{ddd}, 11.0,11.0,4.8)$ & $14,16 a, 16 b$ & 13 & $14,16 b, 17$ & $9,10 a, 10 b, 11,12,13,14,16 a, 16 b, 17,22 a, 25,26$ \\
\hline $16 a$ & $30.5(t)$ & $2.30(o b)$ & $15,16 b, 17$ & 15,17 & $13,16 b$ & $\begin{array}{l}\text { 10a, 10b, 11, 12, 13, 14, 15, 16b, 17, 18, 19a, 19b, 22a, } \\
22 \mathrm{~b}, 25,26\end{array}$ \\
\hline $16 b$ & & $1.96(o b)$ & $15,16 \mathrm{a}, 17$ & 14,15 & $15,16 a, 17,26$ & $\begin{array}{l}\text { 10a, 10b, 11, 12, 13, 14, 15, 16a, 17, 18, 19a, 19b, 22a, } \\
22 b, 25,26\end{array}$ \\
\hline 17 & $81.3(d)$ & $4.03(\mathrm{ddd}, 11.8,7.5,1.4)$ & $16 a, 16 b, 18$ & 19 & $18,19 a$ & $12,13,14,15,16 a, 16 b, 18,19 a, 19 b, 20,21,25,26$ \\
\hline 18 & $38.0(d)$ & $2.59\left(m^{d}\right)$ & $17,19 a, 19 b, 26$ & 17,26 & $17,19 a, 20,26$ & $16 a, 16 b, 17,18,19 a, 19 b, 20,21,25,26$ \\
\hline $19 a$ & $35.6(t)$ & $2.16(\mathrm{ddd}, 12.2,6.9,6.9)$ & $18,19 b, 20$ & 17,20 & $18,19 a, 20$ & $16 a, 16 b, 17,18,19 a, 20,21,22 a, 22 b, 23,25,26$ \\
\hline $19 b$ & & $1.34(\mathrm{ob})$ & $18,19 a, 20$ & 26 & $7^{\prime}, 12,19 a, 20,21,22$ & $16 a, 16 b, 17,18,19 b, 20,21,22 a, 22 b, 23,25,26$ \\
\hline 20 & $81.8(d)$ & $3.82(\mathrm{~m})$ & $19 a, 19 b, 21$ & 21 & $16,17,19 a, 21,22 b$ & $16 b, 18,19 a, 19 b, 21,22 a, 23,26, O H-21$ \\
\hline
\end{tabular}




\begin{tabular}{|c|c|c|c|c|c|c|}
\hline 21 & $74.7(d)$ & $3.58\left(m^{e}\right)$ & $20,22 \mathrm{~b}, \mathrm{OH}-21$ & & $10 a, 13,16 a, 19 a, 19 b, 23,26$ & $16 b, 18,19 a, 19 a, 21,22 a, 23,26, O H-21$ \\
\hline $22 a$ & $32.1(t)$ & $1.87(\mathrm{~m})$ & $22 \mathrm{~b}, 23, \mathrm{OH}-21$ & & $22 b$ & $20,21,22 \mathrm{~b}, 23,24, \mathrm{OH}-21$ \\
\hline $22 b$ & & $1.74(\mathrm{ob})$ & $21,22 a, 23$ & & $4 a, 22 a$ & $20,21,22 \mathrm{a}, 23,24, \mathrm{OH}-21$ \\
\hline 23 & $79.6(d)$ & $4.82(\mathrm{~m})$ & $22 \mathrm{a}, 22 \mathrm{~b}, 24$ & & $3,21,24$ & $16 b, 19 a, 19 b, 20,21,22 a, 22 b, 24, O H-21$ \\
\hline 24 & $71.4(d)$ & 4.41 (br s) & 23 & 1,23 & $3,5,9,23$ & $10 \mathrm{a}, 20,21,22 \mathrm{a}, 22 \mathrm{~b}, 23, \mathrm{OH}-24$ \\
\hline 25 & $19.0(q)$ & $1.04(\mathrm{~d}, 6.6)$ & 11 & $10,11,12$ & $3,9,11,12,13,23$ & $7,8 a x, 8 e q, 9,10 a, 10 b, 11,12,13,14,15,16 a, 16 b$ \\
\hline \multirow[t]{5}{*}{26} & $13.9(q)$ & $1.07(\mathrm{~d}, 6.9)$ & 18 & $17,18,19,20$ & $6 a x, 16 b, 17,18,19 b$ & $10 a, 10 b, 11,12,13,14,15,16 a, 16 b, 17,18,19 a, 19 b, 20$ \\
\hline & $\mathrm{OH}-2$ & $2.82(\mathrm{br} \mathrm{s})$ & & $2^{\prime}$ & $\mathrm{OH}-21, \mathrm{OH}-24$ & $3,4 a, 4 b, 5$ \\
\hline & $\mathrm{OH}-3$ & $3.42(\mathrm{ob})$ & & & $5, \mathrm{OH}-21, \mathrm{OH}-24$ & $4 a$ \\
\hline & $\mathrm{OH}-21$ & $3.07(\mathrm{~s})$ & $21,22 a$ & 22 & $20,21, \mathrm{OH}-2, \mathrm{OH}-24$ & $20,21,22 b$ \\
\hline & $\mathrm{OH}-24$ & 3.33 (br s) & & & $\mathrm{OH}-2, \mathrm{OH}-21$ & 24 \\
\hline $1^{\prime}$ & $96.6(d)$ & $5.10(\mathrm{br} \mathrm{s})$ & $2^{\prime}$ & $7,2^{\prime}, 5^{\prime}, 7^{\prime}$ & $6 e q, 7,2^{\prime}, 6^{\prime}, 7^{\prime}$ & $2^{\prime}, 3^{\prime}, 4^{\prime}, 6^{\prime}$ \\
\hline $2^{\prime}$ & $77.0(d)$ & $3.36(\mathrm{ddd}, 3.5,2.9,1.4)$ & $1^{\prime}, 3^{\prime}$ & $3^{\prime}, 4^{\prime}, 7^{\prime}$ & $1^{\prime}, 3^{\prime}, 7^{\prime}$ & $1^{\prime}, 3^{\prime}, 4^{\prime}$ \\
\hline $3^{\prime}$ & $68.4(d)$ & $5.20\left(m^{f}\right)$ & $2^{\prime}, 4^{\prime}$ & $2^{\prime}$ & $2^{\prime}, 4^{\prime}, 5^{\prime}, 7^{\prime}$ & $1^{\prime}, 2^{\prime}, 5^{\prime}, 6^{\prime}, 4^{\prime \prime}$ \\
\hline $4^{\prime}$ & $69.2(d)$ & $5.19(\mathrm{ob})$ & $3^{\prime}, 5^{\prime}$ & $2^{\prime}, 1^{\prime \prime}$ & $3^{\prime}, 5^{\prime}, 6^{\prime}$ & $1^{\prime}, 2^{\prime}, 3^{\prime}, 5^{\prime}, 6^{\prime}$ \\
\hline $5^{\prime}$ & $65.1(d)$ & $4.13(\mathrm{dq}, 6.6,1.1)$ & $4^{\prime}, 6^{\prime}$ & $1^{\prime}, 3^{\prime}, 4^{\prime}, 6^{\prime}$ & $7,8 \mathrm{eq}, 23^{\prime}, 6^{\prime}$ & $1^{\prime}, 2^{\prime}, 3^{\prime}, 4^{\prime}$ \\
\hline $6^{\prime}$ & $16.1(q)$ & $1.18(\mathrm{~d}, 6.6)$ & $5^{\prime}$ & $4^{\prime}, 5^{\prime}$ & $6 \mathrm{eq}, 1^{\prime}, 4^{\prime}, 5^{\prime}$ & $1^{\prime}, 2^{\prime}, 3^{\prime}, 4^{\prime}, 5^{\prime}$ \\
\hline $7^{\prime}$ & $60.2(q)$ & $3.50(\mathrm{~s})$ & $1^{\prime}, 2^{\prime}$ & $1^{\prime}, 2^{\prime}$ & $1^{\prime}, 2^{\prime}$ & $1^{\prime}, 2^{\prime}, 3^{\prime}, 5^{\prime}, 6^{\prime}$ \\
\hline $1^{\prime \prime}$ & $173.7(\mathrm{~s})$ & - & & & & \\
\hline \multirow[t]{2}{*}{$2^{\prime \prime}$} & $36.2(t)$ & $2.43(\mathrm{~m})$ & $3^{\prime \prime}, 4^{\prime \prime}$ & $1^{\prime \prime}, 4^{\prime \prime}$ & $3^{\prime \prime}, 4^{\prime \prime}$ & $3^{\prime \prime}, 4^{\prime \prime}$ \\
\hline & & $2.40(\mathrm{~m})$ & $3^{\prime \prime}, 4^{\prime \prime}$ & & & \\
\hline $3^{\prime \prime}$ & $18.7(t)$ & $1.71(\mathrm{ob})$ & $2^{\prime \prime}, 4^{\prime \prime}$ & $1^{\prime \prime}, 2^{\prime \prime}, 4^{\prime \prime}$ & $2^{\prime \prime}, 4^{\prime \prime}$ & $2^{\prime \prime}, 4^{\prime \prime}$ \\
\hline $4^{\prime \prime}$ & $13.7(q)$ & $0.98(t, 7.5)$ & $3^{\prime \prime}$ & $2 ", 3^{\prime \prime}$ & $2^{\prime \prime}, 3^{\prime \prime}$ & $2^{\prime \prime}, 5^{\prime \prime}$ \\
\hline $1^{\prime \prime \prime}$ & $172.6(\mathrm{~s})$ & - & & & & \\
\hline $2^{\prime \prime \prime}$ & $36.0(\mathrm{t})$ & $2.29(\mathrm{dt}, 7.5,2.8)$ & $3^{\prime \prime \prime}, 4^{\prime \prime \prime}$ & $1^{\prime \prime \prime}, 4^{\prime \prime \prime}$ & $7^{\prime}, 2^{\prime \prime}, 3^{\prime \prime \prime}, 4^{\prime \prime \prime}$ & $3^{\prime \prime \prime}, 4^{\prime \prime \prime}$ \\
\hline $3^{\prime \prime \prime}$ & $18.2(t)$ & $1.65(\mathrm{~m})$ & $2^{\prime \prime \prime}, 4^{\prime \prime \prime}$ & $1^{\prime \prime \prime}, 2^{\prime \prime \prime}, 4^{\prime \prime \prime}$ & $2^{\prime \prime \prime}, 3^{\prime \prime \prime}, 4^{\prime \prime \prime}$ & $2^{\prime \prime \prime}, 4^{\prime \prime \prime}$ \\
\hline $4^{\prime \prime \prime}$ & $13.7(q)$ & $0.95(t, 7.5)$ & $3^{\prime \prime \prime}$ & $2^{\prime \prime \prime}, 3^{\prime \prime \prime}$ & $2^{\prime \prime \prime}, 3^{\prime \prime \prime}$ & $2^{\prime \prime \prime}, 5^{\prime \prime \prime}$ \\
\hline
\end{tabular}

${ }^{\mathrm{a}} \mathrm{HMBC}$ correlations are presented from proton to indicated carbon; ${ }^{\mathrm{b}}$ Partially obscured multiplet, but $J_{\mathrm{HH}}=11.4 \mathrm{~Hz}$ apparent; ${ }^{\mathrm{c}}$ Partially obscured multiplet, but $J_{\mathrm{HH}}=7.5 \mathrm{~Hz}$ apparent; ${ }^{\mathrm{d}} \mathrm{Apparent} J_{\mathrm{HH}}=6.9 \mathrm{~Hz}$; Partially obscured multiplet, but $J_{\mathrm{HH}}=10.0 \mathrm{~Hz}$ apparent; 'Partially obscured multiplet, but $J_{\mathrm{HH}}=3.5 \mathrm{~Hz}$ apparent.

${ }^{*} \mathrm{COSY}$ correlation observed in the ROESY spectrum. 


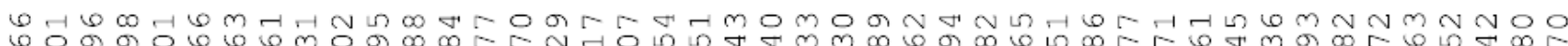

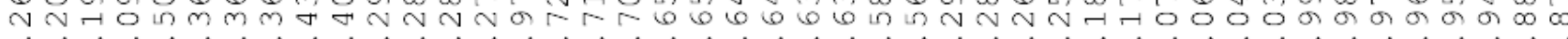
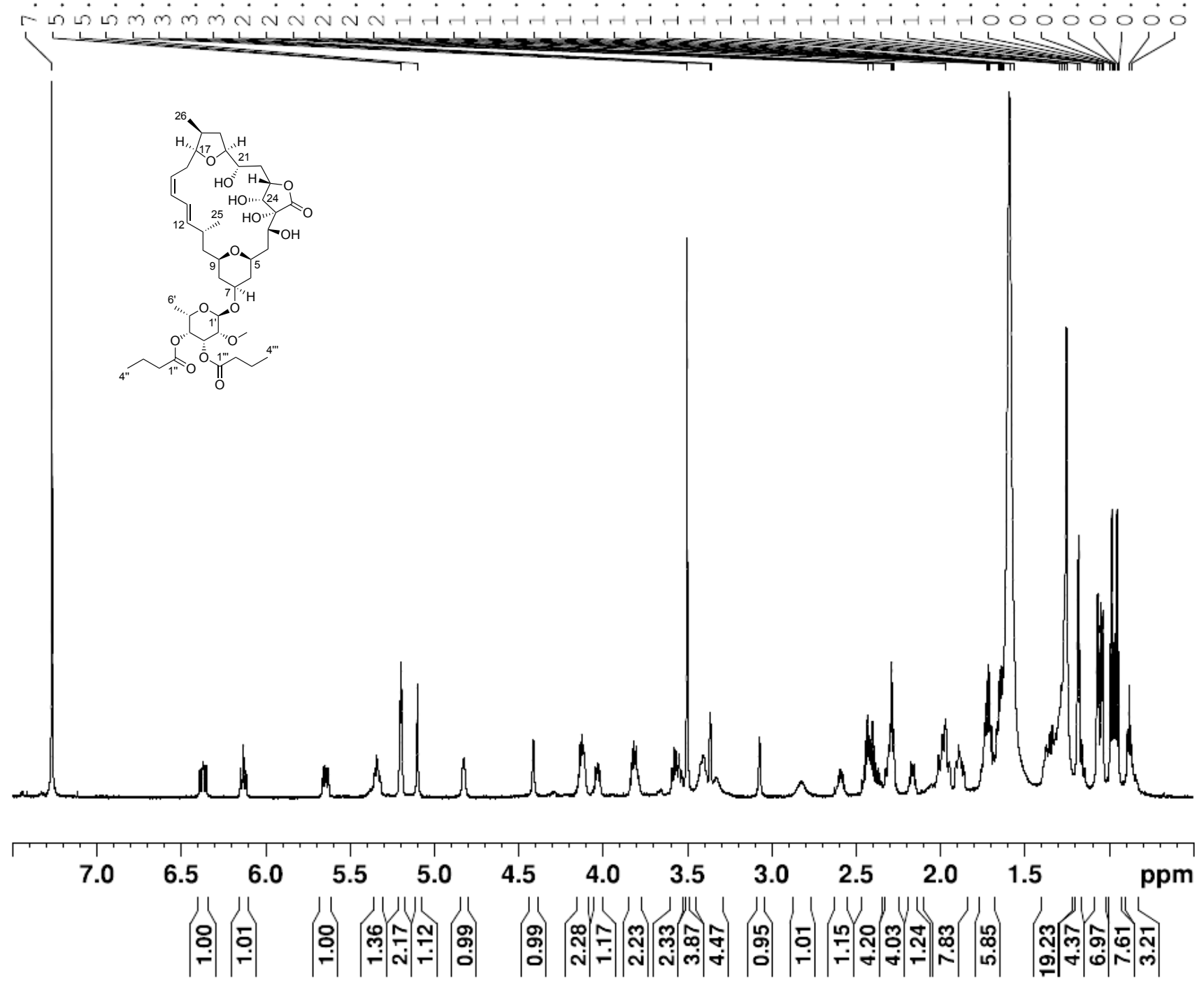

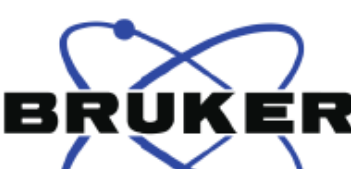

Current Data Parameters NAME EXPNO

2 - Acquisition Parameter

Date_ 20150610

Time 16.18

PROBHD $5 \mathrm{~mm}$ CPDCH $13 \mathrm{C}$

$\begin{array}{rr}\text { PULPROG } & \text { zg30 } \\ \text { TD } & 65536\end{array}$

TD
SOLVENT

NS

SWH $\quad 14423.077 \mathrm{~Hz}$

AQ $\quad 2.2719147 \mathrm{sec}$

RQ

DW $\quad 34.667$ usec

DE

TDO

$\begin{aligned} & 6.50 \text { us } \\ & 293.3 \mathrm{~K}\end{aligned}$

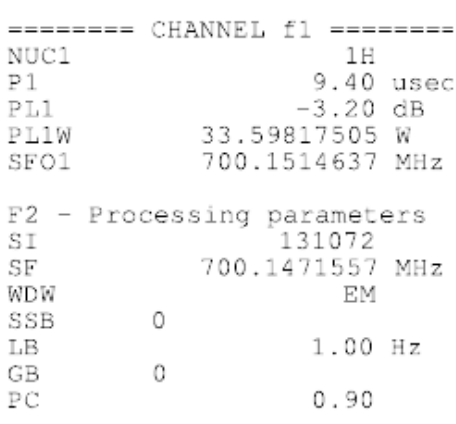

Figure S1. ${ }^{1} \mathrm{H}$ NMR spectrum for mandelalide $\mathrm{E}\left(1,700 \mathrm{MHz}, \mathrm{CDCl}_{3}\right)$ 


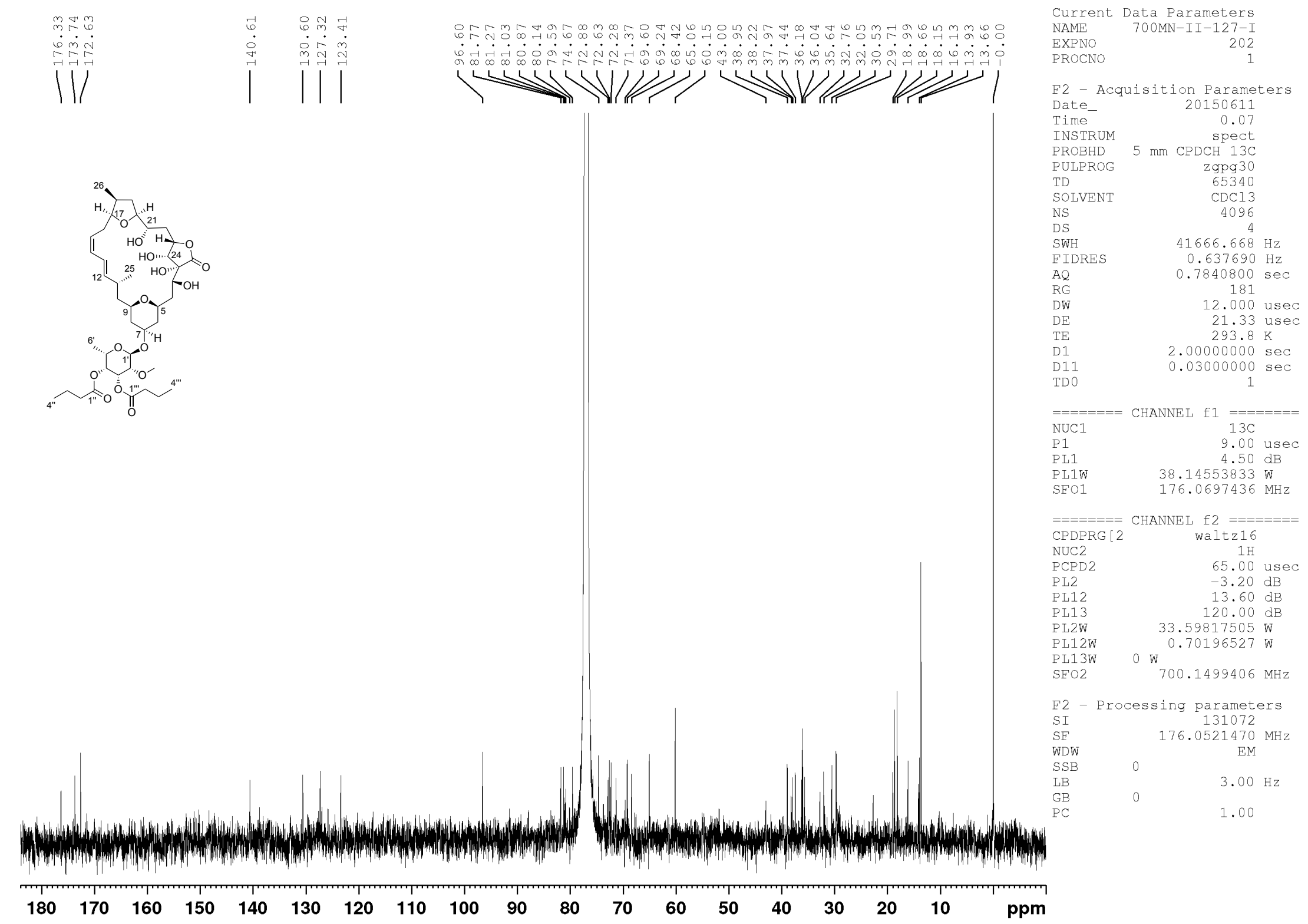

Figure S2. ${ }^{13} \mathrm{C}$ NMR spectrum for mandelalide $\mathrm{E}\left(175 \mathrm{MHz}, \mathrm{CDCl}_{3}\right)$ 


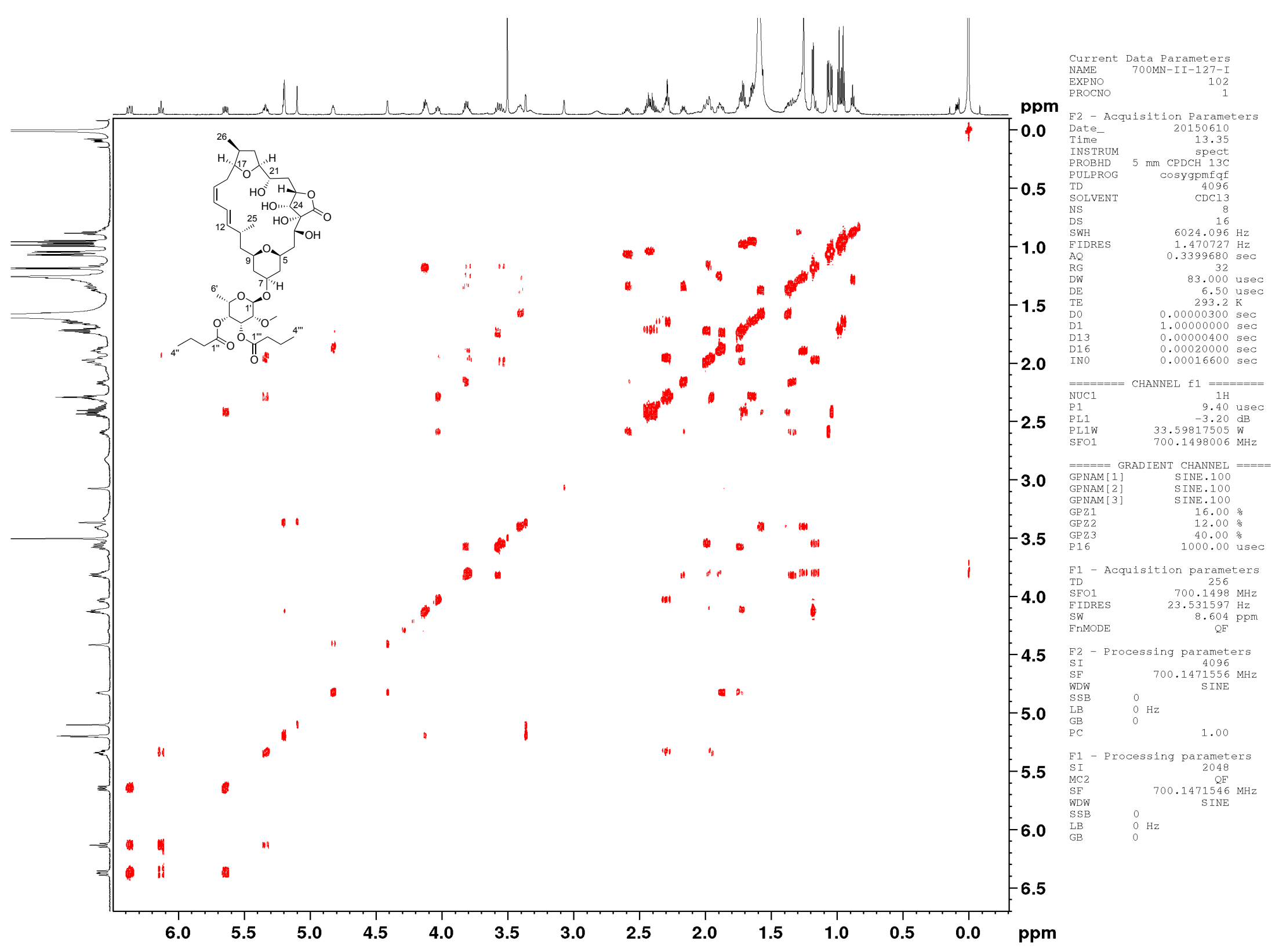

Figure S3. COSY spectrum for mandelalide $\mathrm{E}\left(700 \mathrm{MHz}, \mathrm{CDCl}_{3}\right)$ 


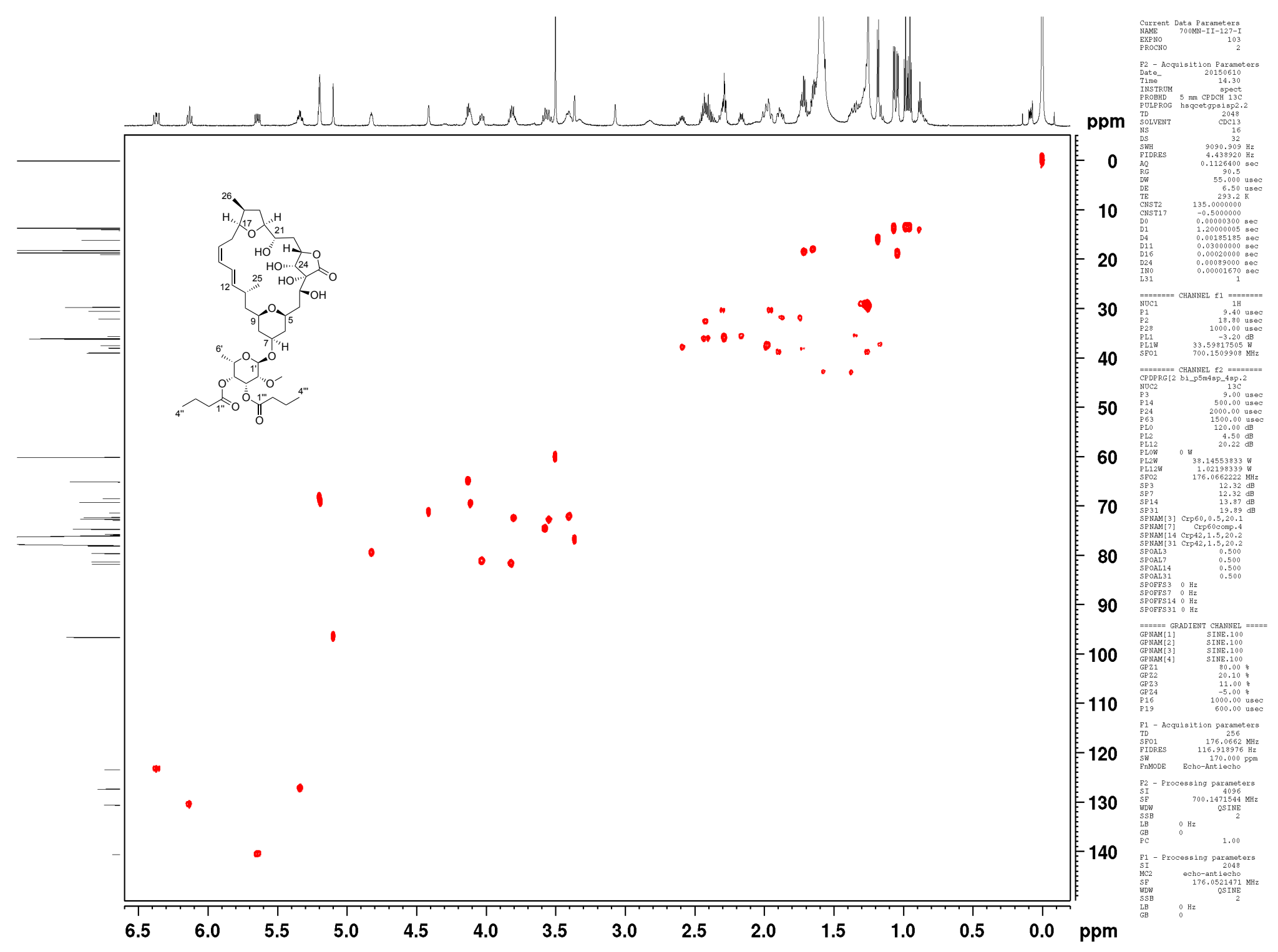

Figure S4. HSQC spectrum for mandelalide $\mathrm{E}\left(700 \mathrm{MHz}, \mathrm{CDCl}_{3}\right)$ 


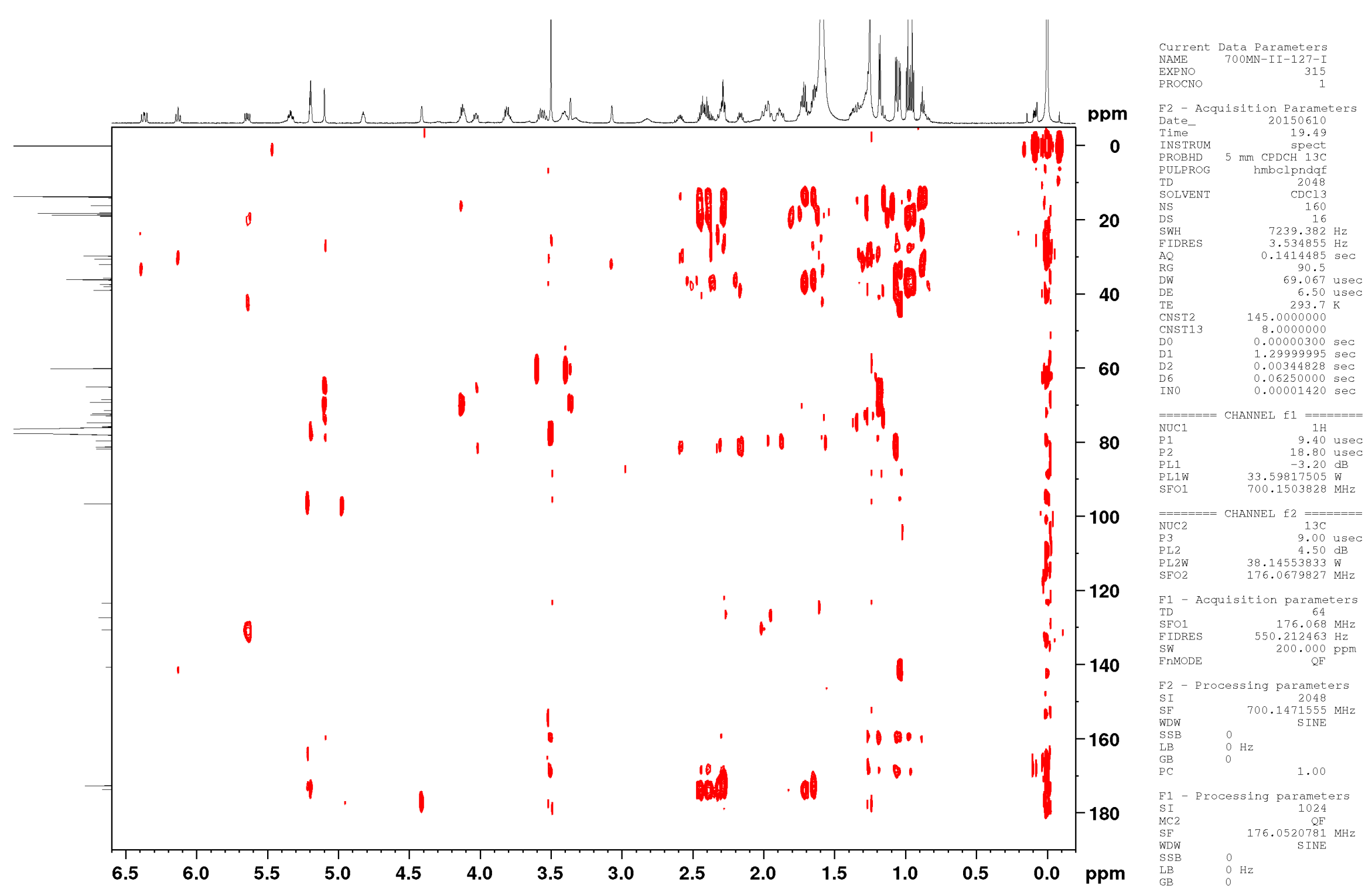

Figure S5. Phase-cycled HMBC spectrum for mandelalide $\mathrm{E}\left(700 \mathrm{MHz}, \mathrm{CDCl}_{3} ;{ }^{2,3} \mathrm{~J}_{\mathrm{CH}}=8 \mathrm{~Hz}\right)$ 


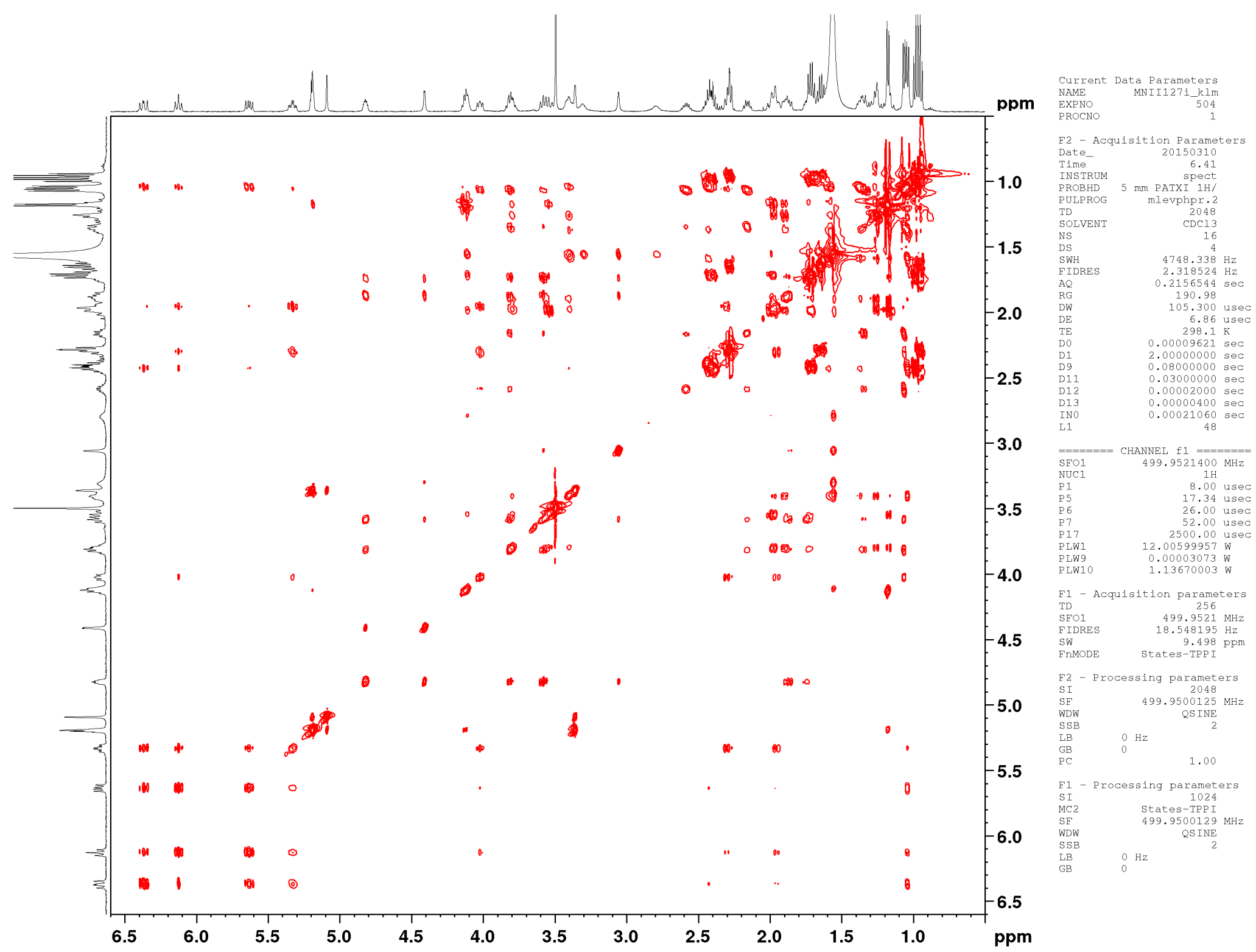

Figure S6. TOCSY spectrum for mandelalide $\mathrm{E}$, mixing time $=80 \mathrm{~ms}\left(500 \mathrm{MHz}, \mathrm{CDCl}_{3}\right)$ 


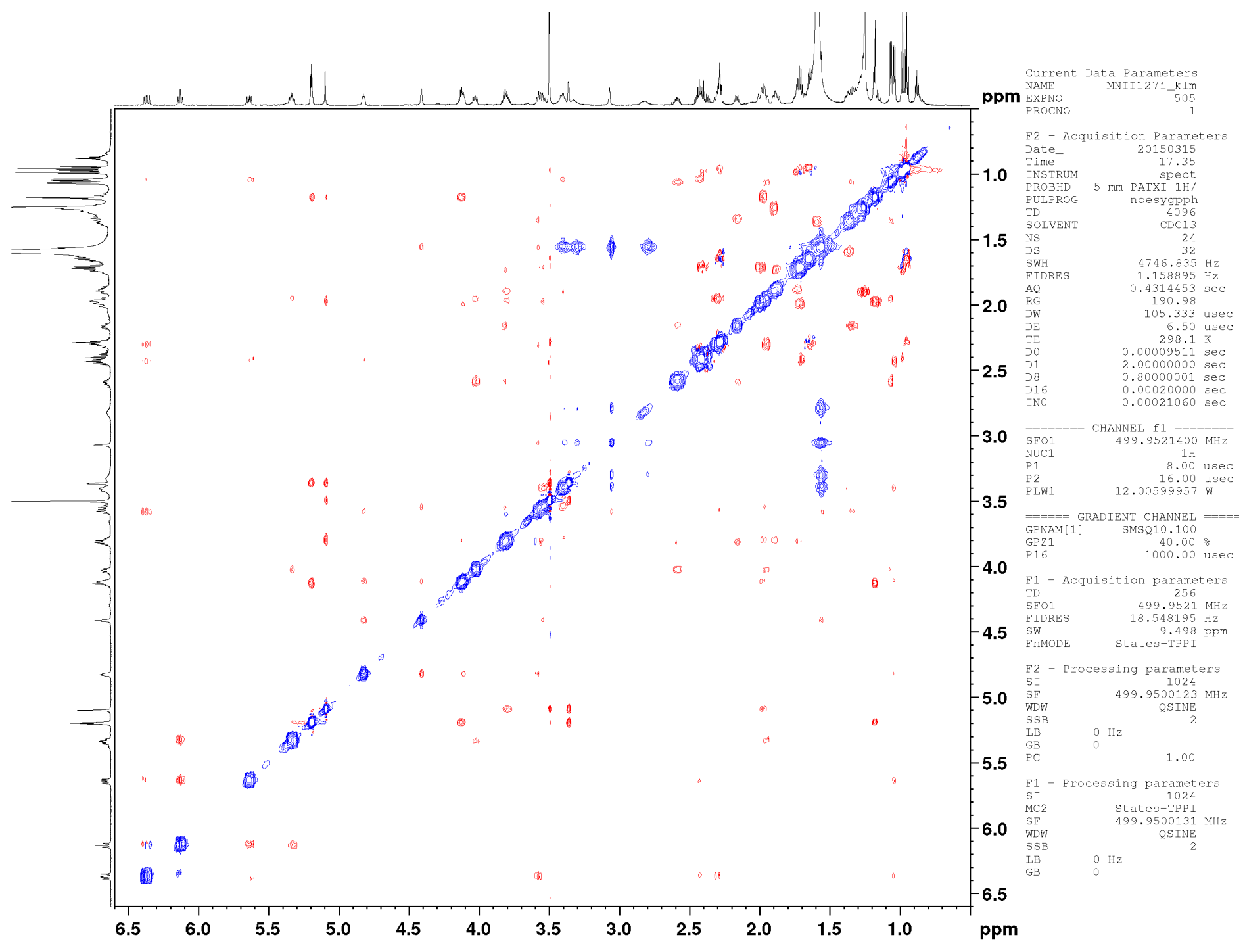

Figure S7. NOESY spectrum for mandelalide $\mathrm{E}\left(500 \mathrm{MHz}, \mathrm{CDCl}_{3}\right.$, mixing time $\left.=800 \mathrm{~ms}\right)$. 

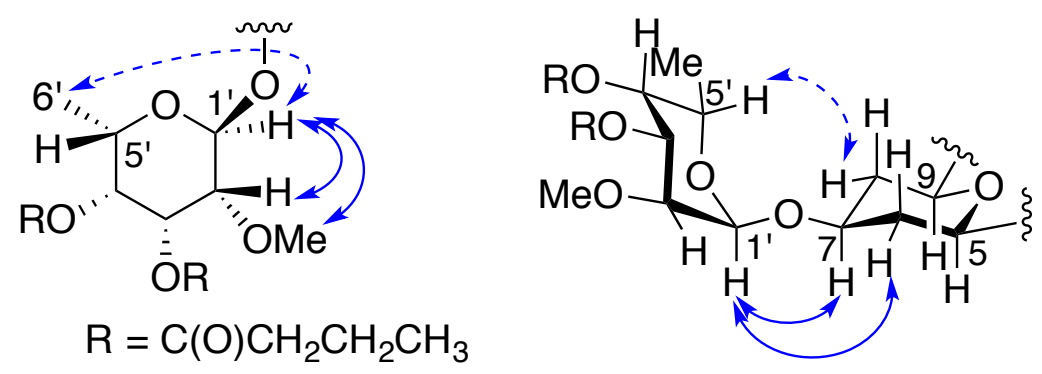

Figure S8. Key NOESY correlations for the mandelalide E glycoside. Dashed lines indicate weak NOESY correlations versus solid lines for prominent correlations.

\section{Biological Evaluation Materials and Methods}

Compounds. A small amount of residual natural product mandelalide $A$ from the original isolation was used without HPLC purification due to the small amount available. Mandelalides $B$, C and E, freshly isolated from the 2013 tunicate recollection, were re-purified by HPLC, concentrated and weighed, immediately before biological testing. Synthetic mandelalide A provided by Professor Tao $\mathrm{Ye}^{2}$ was purified and also co-injected with natural mandelalide $\mathrm{A}$ on HPLC, (Figure S9), and a CD spectrum collected (Figure S10), before it was submitted for biological screening. The compounds for assays were prepared at $3 \mathrm{mM}$ in $100 \%$ sterile-filtered DMSO (D2438 Sigma-Aldrich Corp., St. Louis, MO) and stored at $-20{ }^{\circ} \mathrm{C}$. For concentrationresponse analyses, serial dilutions of each compound were prepared in DMSO on the day of the experiment for addition to cell culture plates; final concentrations of DMSO in the culture medium never exceeded $0.1 \%$.

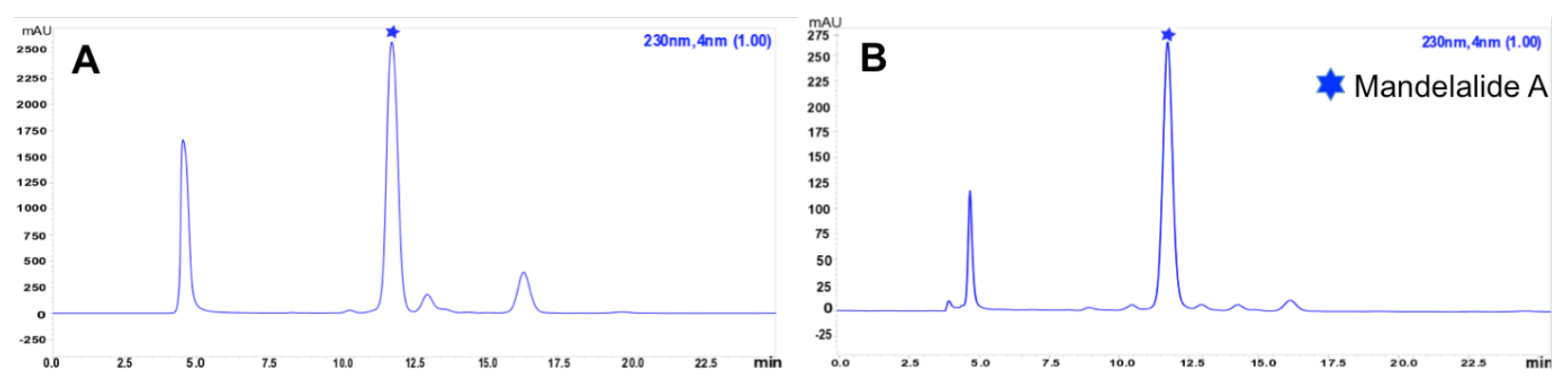

Figure S9. HPLC profile for A) synthetic mandelalide A provided by Professor Tao $\mathrm{Ye}^{2}$ and $\mathrm{B}$ ) co-injection of synthetic Ye product and natural mandelalide $A^{1}$ showing co-elution $\left(t_{R}, 12 \mathrm{~min}\right.$ ) in 7:3 MeOH-H2O at $0.6 \mathrm{~mL} / \mathrm{min}$, column: Phenomenex Synergi Hydro, $4.6 \times 250 \mathrm{~mm}$, absorbance $230 \mathrm{~nm}$. 

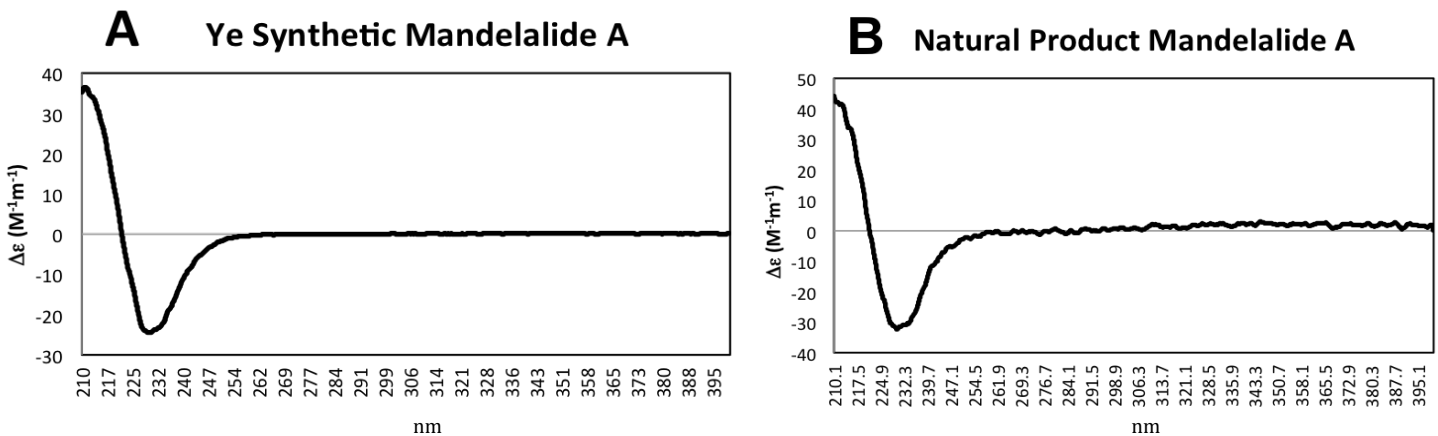

Figure S10. CD spectra in $\mathrm{MeOH}$ for: A) synthetic mandelalide $A(4 \mathrm{mg} / \mathrm{mL}),{ }^{2}$ and $\left.B\right)$ natural mandelalide $\mathrm{A}(0.5 \mathrm{mg} / \mathrm{mL}){ }^{1}$

Mammalian cell culture. Human non-small cell lung cancer $\mathrm{NCl}-\mathrm{H} 460$ cells were from the National Cancer Institute cell line repository (Frederick, MD). Human U87-MG glioblastoma, HCT116 colon, HeLa cervical cancer cell lines, and mouse Neuro-2A neuroblastoma cell lines were from the American Type Culture Collection (ATCC, Manassas, VA). U87-MG, HeLa, and Neuro-2A cells were grown in Minimal Essential Medium Eagle with 10\% fetal bovine serum Lglutamine $(2 \mathrm{mM})$, and $1 \%$ penicillin/streptomycin. $\mathrm{NCl}-\mathrm{H} 460$ cells were cultured in RPMI-1640 supplemented with L-glutamine $(2 \mathrm{mM})$, sodium pyruvate $(1 \mathrm{mM})$, sodium bicarbonate $(1.5 \mathrm{~g} / \mathrm{L})$, $1 \%$ penicillin/streptomycin and 10\% FBS. HCT116 cells were grown in McCoy's 5a medium supplemented with 10\% FBS and 1\% penicillin/streptomycin. Cell culture medium was purchased from Mediatech Inc (Manassas, VA), FBS was from HyClone (Logan, UT) and general culture supplies were from Thermo Fisher Scientific (Waltham, MA). All cells were maintained in a humidified chamber at $37{ }^{\circ} \mathrm{C}$ with $5 \% \mathrm{CO}_{2}$.

Cell viability assays. The cytotoxicity of mandelalides $B, C$, and $E$ was evaluated in four human cancer cell lines using a previously described protocol subjected to slight modifications. ${ }^{[3]}$ Cells were seeded into 96 -well plates $18 \mathrm{~h}$ prior to treatment at densities adjusted for the growth rates of each particular cell type: 25,000 cells per well for $\mathrm{NCl}-\mathrm{H} 460$, 15,000 cells per well for U87-MG and HCT116 and 10,000 cells per well for HeLa cells. Cell viability was determined after $72 \mathrm{~h}$ treatment using a standard 3-(4,5-dimethylthiazol-2-yl)2,5 ,diphenyl tetrazolium bromide (MTT) assay. ${ }^{3}$ For analysis of the influence of cell density on mandelalide-induced cytotoxicity, the activity of natural (McPhail) and synthetic mandelalide $A$ (Ye lab) was compared in human $\mathrm{NCl}-\mathrm{H} 460$ and mouse neuro-2A cells seeded at high $(25,000$ cells per well) and low (3,000 cells per well) density. Cell viability was determined after $48 \mathrm{~h}$ 
treatment using a WST-8 assay (Cayman Chemical Co., Ann Arbor, MI). The WST-8 utilizes the same principle as the MTT assay, however WST-8 is a water-soluble tetrazolium salt that is reduced outside the cell to generate a formazan dye in the presence of viable, metabolically active cells. In all studies the cytotoxicity of pure compounds was assessed in at least three independent cultures with the viability of vehicle-treated control cells defined as $100 \%$. Concentration response curves (Figure S11) were plotted using GraphPad Prism version 5.04.

\section{Concentration-Response Curves for Natural Mandelalides}

A

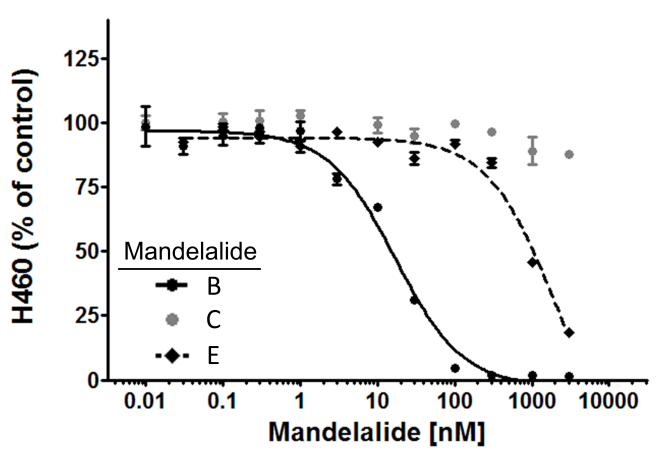

C

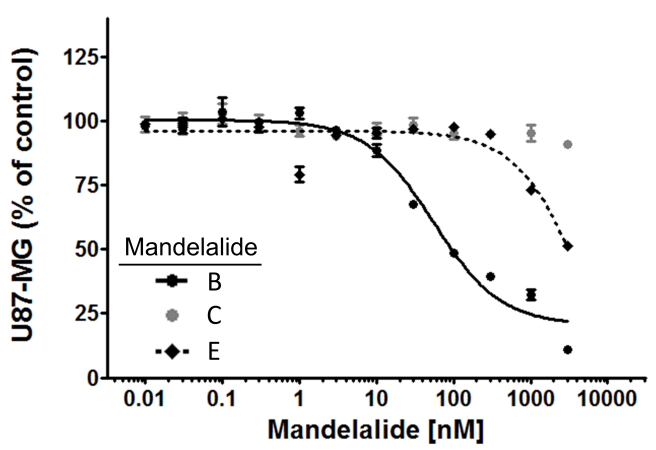

B

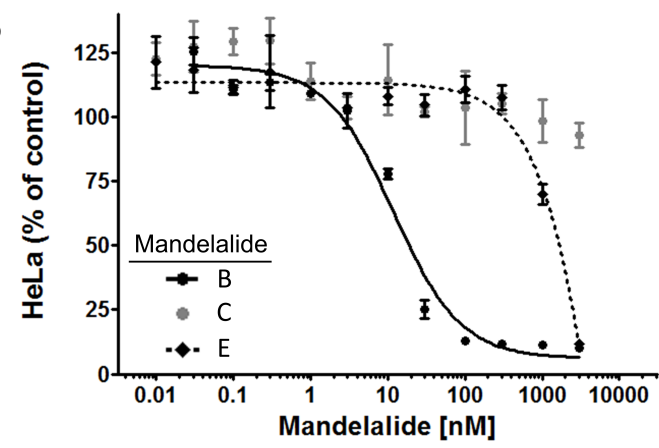

$\mathrm{D}$

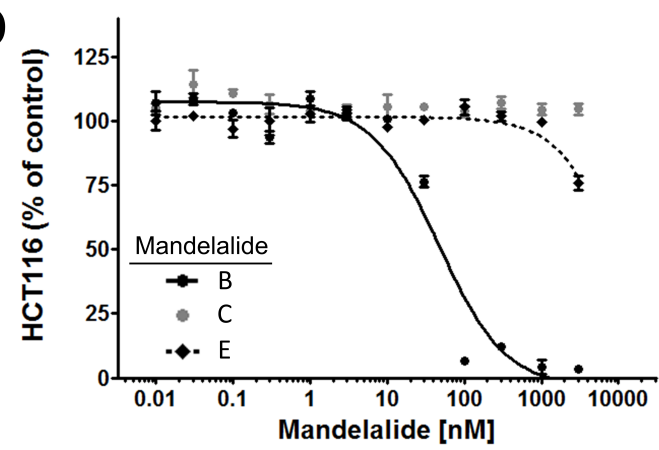

Figure S11. Cytotoxicity of natural mandelalides B, C and E. Concentration-response relationships for mandelalide $B$ (black circles), mandelalide $C$ (gray circles) and mandelalide $\mathrm{E}$ (black diamonds) against human: (A) NCl-H460 lung, (B) HeLa cervical, (C) U87-MG glioblastoma and (D) HCT116 colon cancer cells. Cells were seeded into 96-well plates at high starting density and exposed to increasing concentrations of compound or vehicle for $72 \mathrm{~h}$. Cytotoxicity was determined by MTT assay with the viability of vehicle-treated cells defined as $100 \%$. Dose-response data represent mean viability $\pm S E$ ( $n=3$ wells per treatment) from at least three independent experiments.

Comparative analysis of the cytotoxic potential of natural and synthetic mandelalide A. 
The cytotoxic potential of natural and synthetic mandelalide $A$ was compared against mouse neuro-2A neuroblastoma (Figure S12, panels $A$ and $B$ ) and human $\mathrm{NCl}-\mathrm{H} 460$ lung cancer cells (Figure S12, panels $C$ and D) under two different assay conditions. Cells were seeded into standard 96-well plates at low starting density (3,000 cells per well), or at high starting cell densities (25,000 cells per well) reflecting the assay conditions utilized in our original cytotoxicity screen. ${ }^{3}$

Table 2. Cell density is a major determinant of mandelalide-induced cancer cell toxicity.

Cancer Cell Line; $\mathrm{EC}_{50}(95 \%$ C.I.)

\begin{tabular}{l|l|l|l|l}
\cline { 2 - 5 } \multicolumn{2}{l|}{ NCI-H460 Human lung } & \multicolumn{2}{l}{ Neuro-2A Mouse neuroblastoma } \\
\hline Mandelalide A & $3 \times 10^{3}$ & $2.5 \times 10^{4}$ & $3 \times 10^{3}$ & $2.5 \times 10^{4}$ \\
& cells/well & cells/well & cells/well & cells/well \\
\hline Natural & Inactive & $56.2 \mathrm{nM}$ & $* 39 \mathrm{nM}$ & $28 \mathrm{nM}$ \\
\hline Ye & Inactive & $(40-79)$ & $(28-53)$ & $(17-45)$ \\
Product & & $(4.8-20)$ & $(4.9-18)$ & $(2.6-9.7)$ \\
\hline
\end{tabular}

${ }^{*}$ Reduced efficacy against cells seeded at low density

Note that the disparity between level of cytotoxicity for natural versus synthetic mandelalide $A$ in Table 2 arises from use of the very small amount ( $\sim 50 \mathrm{mg})$ of original (not re-purified) natural mandelalide $\mathrm{A}$ available at the time of testing in parallel with the $\mathrm{Ye}^{2}$ synthetic product, which we first purified by reversed-phase HPLC (see supporting information). 

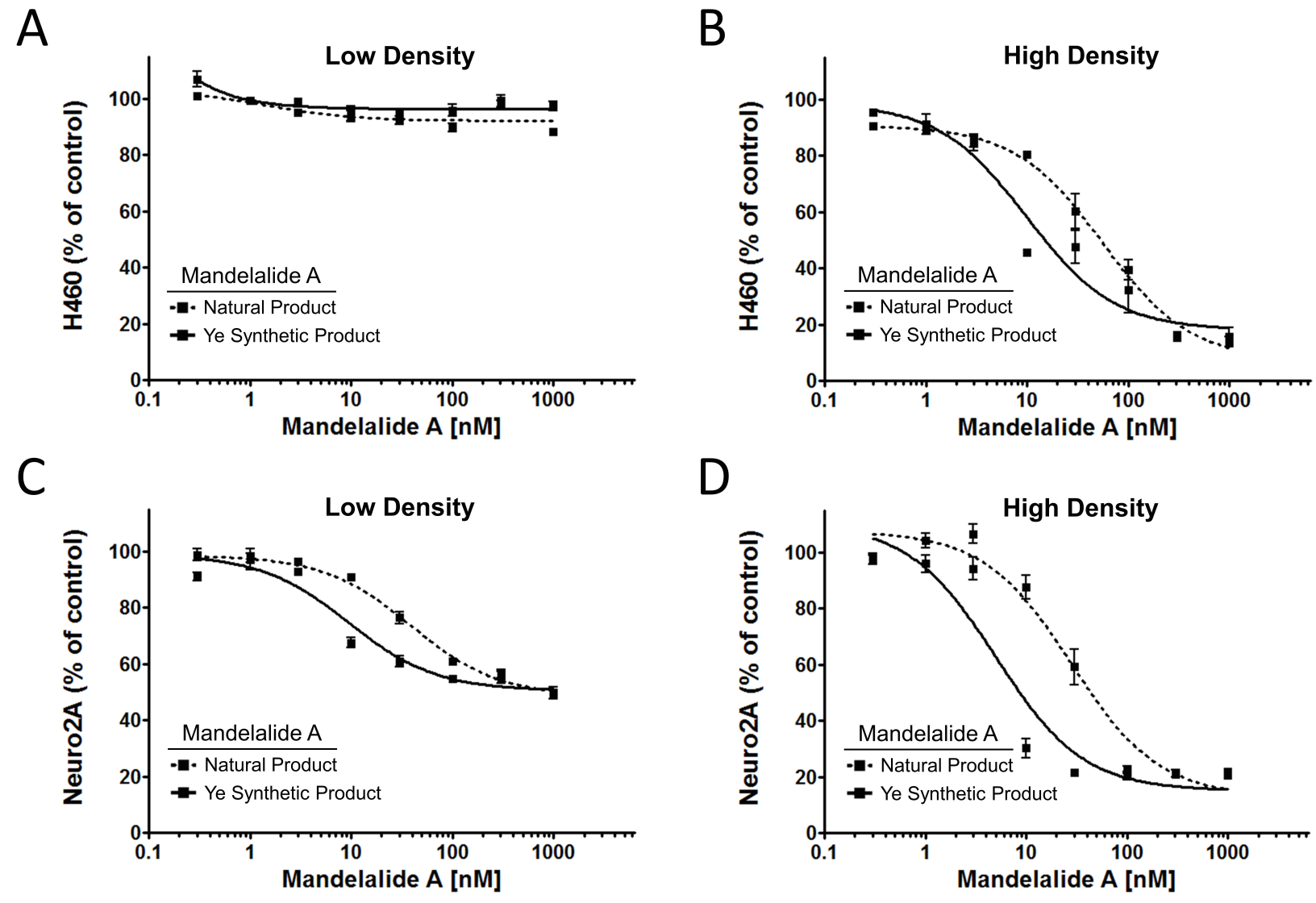

Figure S12. Relationship of cell density to mandelalide A-induced cytotoxicity.

Concentration-response relationships for natural mandelalide $A^{1}$ (dashed line, not re-purified) and a synthetic mandelalide $A^{2}$ (purified) provided by Prof. Tao Ye (solid line) against human $\mathrm{NCl}-\mathrm{H} 460$ and mouse neuro-2A cells cells seeded at low (panels A and C) or high (panels B and D) density. Cells were seeded into 96-well plates at 3,000 cells per well (low density) or 25,000 cells per well (high density) and exposed to increasing concentrations of compound or vehicle for $48 \mathrm{~h}$. Cytotoxicity was determined by WST-8 assay with the viability of vehicletreated cells defined as $100 \%$. Concentration-response data represent mean viability \pm SE $(n=$ 3 wells per treatment) from at least three independent comparisons.

\section{References}

1. Sikorska, J.; Hau, A. M.; Anklin, C.; Parker-Nance, S.; Davies-Coleman, M. T.; Ishmael, J. E.; McPhail, K. L. J. Org. Chem. 2012, 77, 6066-6075.

2. Lei, H.; Yan, J.; Yu, J.; Liu, Y.; Wang, Z.; Xu, Z.; Ye, T. Angew. Chem. Int. Ed. Engl. 2014, $53,6533-6537$.

3. Thornburg, C. C.; Thimmaiah, M.; Shaala, L. A.; Hau, A. M.; Malmo, J. M.; Ishmael, J. E.; Youssef, D. T.; McPhail, K. L. J. Nat. Prod. 2011, 74, 1677-1685. 